\title{
Aerodynamic and Aeroelastic Characteristics of a Tension Cone Inflatable Aerodynamic Decelerator
}

\author{
Ian G. Clark* \\ Georgia Institute of Technology, Atlanta, GA 30332-0150 \\ Juan R. Cruz ${ }^{\dagger}$ and Monica F. Hughes ${ }^{\dagger}$ \\ NASA Langley Research Center, Hampton, VA 23681-2199 \\ Joanne S. Ware ${ }^{\ddagger}$ and Albert Madlangbayan ${ }^{\S}$ \\ ILC Dover, Frederica, DE 19946-2080 \\ and \\ Robert D. Braun $₫$ \\ Georgia Institute of Technology, Atlanta, GA 30332-0150
}

\begin{abstract}
The supersonic aerodynamic and aeroelastic characteristics of a tension cone inflatable aerodynamic decelerator were investigated by wind tunnel testing. Two sets of tests were conducted: one using rigid models and another using textile models. Tests using rigid models were conducted over a Mach number range from 1.65 to 4.5 at angles of attack from -12 to 20 degrees. The axial, normal, and pitching moment coefficients were found to be insensitive to Mach number over the tested range. The axial force coefficient was nearly constant $\left(C_{A}=1.45 \pm 0.05\right)$ with respect to angle of attack. Both the normal and pitching moment coefficients were nearly linear with respect to angle of attack. The pitching moment coefficient showed the model to be statically stable about the reference point. Schlieren images and video showed a detached bow shock with no evidence of large regions of separated flow and/or embedded shocks at all Mach numbers investigated. Qualitatively similar static aerodynamic coefficient and flow visualization results were obtained using textile models at a Mach number of 2.5. Using inflatable textile models the torus pressure required to maintain the model in the fully-inflated configuration was determined. This pressure was found to be sensitive to details in the structural configuration of the inflatable models. Additional tests included surface pressure measurements on rigid models and deployment and inflation tests with inflatable models.
\end{abstract}

\section{Nomenclature}

$C_{A} \quad=$ axial force coefficient

$C_{N} \quad=$ normal force coefficient

$C_{m} \quad=$ pitching moment coefficient

$C_{p} \quad=$ pressure coefficient

$D_{A} \quad=$ aeroshell diameter

\footnotetext{
* Graduate Student, Guggenheim School of Aerospace Engineering, AIAA Student Member, Ian.Clark@GATech.edu

${ }^{\dagger}$ Aerospace Engineer, Atmospheric Flight and Entry Systems Branch, Juan.R.Cruz@NASA.gov

${ }^{\dagger}$ Aerospace Engineer, Atmospheric Flight and Entry Systems Branch, Monica.F.Hughes@NASA.gov

* Senior Materials Development Engineer, AIAA Member, WareJ@ILCDover.com

§ Design Engineer, MadlaA@ILCDover.com

"Associate Professor, Guggenheim School of Aerospace Engineering, AIAA Fellow, Robert.Braun@AE.GATech.edu
} 


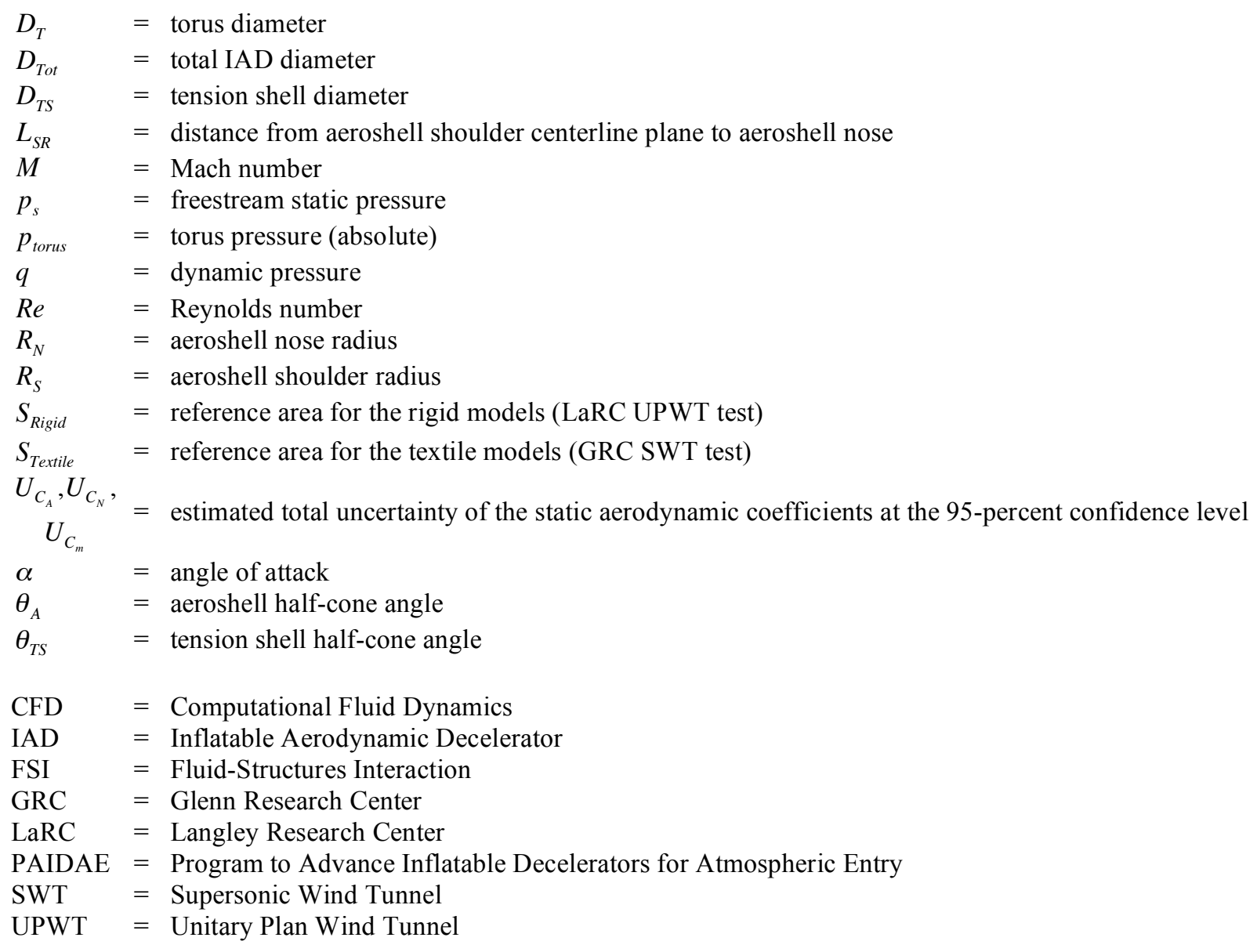

\section{Introduction}

C YSTEMS studies ${ }^{1}$ have shown the benefits of using supersonic inflatable aerodynamic decelerators (IADs) in high-ballistic coefficient entry systems at Mars. These benefits accrue from the ability of supersonic IADs to operate and provide high drag at Mach numbers larger than those possible for parachutes. One possible IAD configuration is the tension cone shown in figure 1: an inflatable torus attached to the aeroshell by a single-surface tension shell. Wind tunnel tests of a tension cone IAD were conducted at the NASA Langley Unitary Plan Wind Tunnel (LaRC UPWT) ${ }^{2}$ and the NASA Glenn 10- by 10-ft Supersonic Wind Tunnel (GRC SWT) ${ }^{3}$. Both sets of tests were conducted using the same tension cone IAD nominal geometry. The goals of these tests were to increase understanding of the aerodynamic and aeroelastic characteristics of tension cone IADs and to provide data for the validation of Computational Fluid Dynamics (CFD) and Fluid-Structure Interaction (FSI) analyses. Tests conducted in the LaRC UPWT used rigid models to obtain static aerodynamic coefficients and surface pressure coefficients. Tests conducted in the GRC SWT used textile models to obtain time histories of forces and moments during deployment and inflation, the minimum pressure required to prevent torus collapse, and the static aerodynamic coefficients. Schlieren photographs from both sets of tests were also acquired. This paper is a brief summary of an extensive test program - a complete description of the tests and results is being prepared as a series of NASA reports.

\section{Tension Cone IAD Geometry}

The tension cone IAD geometry used is defined in figure 1 and table 1 . A rigid aeroshell is attached to the inflatable torus by a tension shell. The shape of the tension shell was defined using the linear shell theory of reference 4 in conjunction with CFD analyses under the constraint of zero circumferential stress across the tension shell at zero angle of attack. Data from reference 5 and CFD analyses were used to minimize the possibility that large regions of separated flow and embedded shocks would form on the tension shell at the test Mach numbers. 
The torus diameter was defined by the minimum diameter that could be fabricated for the inflatable textile models used in the GRC SWT tests (see section IV.A.).

\section{Rigid Models Tests - LaRC UPWT}

\section{A. Models}

Two aluminum rigid models of six-inch total diameter were fabricated for the LaRC UPWT tests: one for static aerodynamic coefficients and another for surface pressure coefficients. In external configuration both models were essentially identical. Photographs of the static aerodynamic coefficients model are shown in figure 3 . The cylinder aft on the downstream side of the model is the windshield. This windshield prevented undesired aerodynamic forces and moments from being measured by the wind tunnel balance on the static aerodynamic coefficients model. The windshield was also present on the surface pressure coefficients model to maintain geometric similarity with the static aerodynamic coefficients model. On the surface pressure coefficients model there were 82 pressure ports organized in three spokes at $0,90,225$ degrees from vertical as shown in figure 4 . There were pressure ports on both the front and back sides of the model.

\section{B. Test Conditions}

Tests were conducted at Mach numbers from 1.65 to 4.5, and Reynolds number (calculated using the model total diameter, $D_{T o t}$, as the reference length) from 0.54 to $1.0 \times 10^{6}$. Data were obtained at angles of attack from - 12 to

20 degrees. For surface pressure runs the model was tested both upright and inverted. This allowed for the use of symmetry to determine surface pressures along a model cross-section without having to place pressure ports along two radials 180 degrees apart.

\section{Static Aerodynamic Coefficients}

The static aerodynamic coefficients were calculated using the model total area $\left(S_{\text {Rigid }}=\pi D_{\text {Tot }}^{2} / 4\right)$ as the reference area, and the model total diameter $\left(D_{T o t}\right)$ as the reference length for pitching moment calculations. In figure 5 , static aerodynamic coefficient results are shown in the angle of attack range from 0 to 20 degrees and Mach numbers of 1.65, 2.5, and 4.5. The axial force coefficient is seen to be nearly constant with respect to angle of attack. Both the normal force coefficient and the pitching moment coefficient are nearly linear with respect to angle of attack. The approximate slopes of the normal force and pitching moment coefficients are $0.00267 \mathrm{deg}^{-1}\left(0.153 \mathrm{rad}^{-1}\right)$ and $-0.00222 \mathrm{deg}^{-1}\left(-0.115 \mathrm{rad}^{-1}\right)$, respectively, at a Mach number of 2.5. The negative slope of the pitching moment coefficient implies that the model is statically stable about the pitching moment reference point (see figure 1). All three static aerodynamic coefficients can be seen to be fairly insensitive to Mach number over the range from 1.65 to 4.5 .

\section{Surface Pressure Coefficients}

Surface pressure coefficients are shown in figure 6 for the vertical spoke at approximately zero degree angle of attack and Mach numbers of 1.65, 2.5, and 4.5. Surface pressures across the forebody are seen to be smooth with the exception of a slight change in slope at the tension shell/aeroshell junction. Aftbody pressures were nearly constant for a given Mach number. In figure 7 surface pressure coefficients are shown for the vertical spoke at angles of attack of 0,12 , and 20 degrees and a Mach number of 2.5. At 12-degree angle of attack the largest surface pressures are located on the windward conical portion of the aeroshell forebody while at 20-degree angle of attack they have transitioned to the tension shell portion of the geometry. At 20-degree angle of attack a very small adverse pressure gradient is observed on the leeward side of the model in the vicinity of the tension shell/aeroshell junction. Aftbody pressures are seen to be essentially constant versus angle of attack.

\section{E. Flow Visualization}

Three schlieren images are shown in figure 8 at approximately zero degree angle of attack and Mach numbers of $1.65,2.5$, and 4.5. Prominent flow features include the progression of the bow shock, flow expansion around the shoulder, and the boat-tail structure of the trailing shocks. Figure 9 shows three schlieren images taken at Mach 2.5 and angles of attack of $0.3,12.2$, and 20.2 degrees. The bow shock remained detached and the overall shock structure was observed to be stable at all test conditions. These results highlight the success in developing a tension cone configuration that was free of large regions of separated flow and/or embedded shocks on the tension shell as observed on some prior geometries tested..$^{5}$ 


\section{A. Models}

\section{Textile Models Tests - GRC SWT}

Two types of textiles models were used in the GRC SWT tests: semi-rigid and inflatable. Because of the model fabrication techniques used, the models approximated the geometry specified in section II as a sixteen-sided polygon of 23.62-inch diameter (as-designed) across the flat portions of the polygon. Figure 10 shows front and rear views of a semi-rigid model. The semi-rigid models were fabricated using a textile tension shell and a rigid torus. Figure 11 shows front and rear views of an inflatable model. On the inflatable models textile material was used for both the tension shell and torus. Inflatable models also included two textile inflation tubes 180 degrees apart. These inflation tubes are attached to the windshield, which is not connected to the metric end of the wind tunnel balance. The textile material used for all models was urethane-coated Kevlar ${ }^{\circledR}$. Temperature limitations of the textile material restricted the maximum Mach number of the GRC SWT test to 2.5.

As shown in figure 1, the tension shell pulls on only one side of the torus. This asymmetric loading causes a torque on the torus, which may cause it to rotate. To investigate this effect some of the models were fitted with anti-torque panels as shown in figure 12. As discussed in section IV.D these anti-torque panels have significant influence on the torus pressure required to maintain the model in the fully-inflated configuration.

\section{B. Test Conditions}

Tests were conducted at Mach numbers of 2.0 and 2.5, and Reynolds number (calculated using the model as-built total diameter, $D_{T o t}$, as the reference length) from 0.54 to $2.1 \times 10^{6}$. Static aerodynamic coefficient data using the semi-rigid models were obtained at angles of attack from -5 to 18 degrees. The angle of attack for tests of the inflatable models was zero degrees. Torus pressure on the inflatable models was varied as required for deployment/inflation and pressure sweep tests.

\section{Static Aerodynamic Coefficients}

The static aerodynamic coefficients were calculated using the as-built model total area ( $S_{\text {Textile }}=4 D_{T o t}^{2} \tan (\pi / 16)$ ), the area of a sixteen-sided polygon) as the reference area, and the as-built model total diameter $\left(D_{T o t}\right)$ as the reference length for pitching moment calculations. In figure 13, static aerodynamic coefficient results are shown for the angle of attack range from -5 to 18 degrees, at a Mach number of 2.44 , a Reynolds number of $1.0 \times 10^{6}$, and a dynamic pressure of $94.0 \mathrm{psf}$. These results were obtained using a semi-rigid model without anti-torque panels. The results are qualitatively similar to those obtained using the rigid model in the LaRC UPWT: nearly constant axial force coefficient and nearly linear normal force and pitching moment coefficients with respect to angle of attack. The approximate slopes of the normal force and pitching moment coefficients are $0.00705 \mathrm{deg}^{-1}\left(0.404 \mathrm{rad}^{-1}\right)$ and $-0.00174 \mathrm{deg}^{-1}\left(-0.0997 \mathrm{rad}^{-1}\right)$, respectively. The negative slope of the pitching moment coefficient implies that the vehicle is statically stable about the pitching moment reference point.

Comparing the nominal axial force coefficient at zero angle of attack obtained using the semi-rigid model (figure 13) against that obtained using the rigid model in the LaRC UPWT test (figure 5) at equivalent Mach and Reynolds numbers, shows that the axial force coefficient of the semi-rigid model without anti-torque panels is approximately 4.8 percent lower than that measured with the rigid model. The normal force and pitching moment coefficient slopes obtained using the semi-rigid model are significantly different than those obtained using the rigid model as can be seen by comparing figures 13 and 5 . These differences in the static aerodynamic coefficient results can be attributed to flexibility effects of the tension shell on the semi-rigid model that influence both the shape of the tension shell and the location of the torus with respect to the rest of the model. Manufacturing dimensional tolerances on the textile models may also play a role in these differences.

\section{Pressure Sweep}

Inflatable models were used for pressure sweep runs. These runs were initiated with sufficiently high torus pressure to maintain the model in the fully-inflated configuration. Torus pressure was slowly reduced until the torus collapsed, and subsequently increased to re-inflate the torus and return the model to the fully-inflated configuration. Figure 14 shows the results for pressure sweep runs for two models: with and without anti-torque panels. In this figure the axial force coefficient is plotted against the torus pressure. Double arrows in figure 14 show the test sequence. When fully inflated the axial force coefficient is insensitive to the torus pressure for both models." The

\footnotetext{
\# Axial force coefficient results for the inflatable models should be interpreted with caution. Because the inflation tubes are not connected to the metric end of the wind tunnel balance, a portion of the axial load on the inflatable model is not being measured. The magnitude of this portion of the axial load is likely to depend on whether the
} 
model with anti-torque panels collapses and re-inflates abruptly, whereas the model without anti-torque panels does so gradually. A lower torus pressure is required to maintain the model with anti-torque panels in the fully-inflated configuration. Considering the lower required torus pressure to maintain the fully-inflated configuration, the IAD with anti-torque panels is structurally advantageous.

\section{E. Deployment and Inflation}

Inflatable models were also used for deployment and inflation runs. The models were stowed by folding them against the sting and wrapping them with a band of Kapton ${ }^{\circledR}$ film. Once the wind tunnel achieved the desired test condition, model deployment was initiated by opening a valve to a reservoir at the desired torus inflation pressure. As the model deployed, the Kapton ${ }^{\circledR}$ film was released allowing the model to develop into its fully-inflated configuration. Figure 15 shows the axial force vs. time for a deployment and inflation test. Inflation occurs in approximately 0.13 seconds. In this run the axial force overshoots the steady-state axial force by about 9 percent for a brief period of time. This overshoot may be due to aerodynamic reasons, a result of inertial loads as the model deploys and inflates, or a combination of both. Results from other runs (not presented here) exhibit variability in the magnitude of this axial force overshoot during inflation.

\section{F. Flow and Model Shape Visualization}

Schlieren images for inflatable models with and without anti-torque panels at a Mach number of approximately 2.5 are shown in figure 16. These images show results similar to those obtained in the LaRC UPWT. There is a detached bow shock and no evidence of large regions of separated flow and/or embedded shocks. Schlieren videos did not show any flow instabilities in the shock structures. Figure 17 shows the model profiles obtained from the schlieren images in figure 16. On the model with anti-torque panels the torus is further forward. There is a marked difference in the profiles of the tension shell between models with and without the anti-torque panels.

\section{Concluding Remarks}

An extensive wind tunnel test program was conducted to determine the aerodynamic and aeroelastic characteristics of a tension cone inflatable aerodynamic decelerator. Results using rigid models showed the axial, normal, and pitching moment coefficients to be insensitive to Mach number over the tested range. The axial force coefficient was nearly constant $\left(C_{A} \approx 1.45 \pm 0.05\right)$ with respect to angle of attack over the range from 0 to 20 degrees. Both the normal and pitching moment coefficients were nearly linear with respect to angle of attack. The pitching moment coefficient showed the model to be statically stable about the reference point. Qualitatively similar static aerodynamic coefficient results were obtained using a textile semi-rigid model. However, some quantitative differences were noticed in the values of the static aerodynamic coefficients, most noticeably in the slopes of the normal and pitching moment coefficients. These differences can be attributed to flexibility effects of the tension shell on the semi-rigid model that influence both the shape of the tension shell and the location of the torus with respect to the rest of the model. Manufacturing dimensional tolerances on the textile models may also play a role in these differences. Schlieren images and video from both the LaRC UPWT and GRC SWT tests showed a detached bow shock with no evidence of large regions of separated flow and/or embedded shocks, verifying one of the stated design goals for the tension cone IAD geometry. The observed effect of anti-torque panels on the torus pressure required to maintain the model in the fully-inflated configuration are important, since this pressure will strongly affect the structural design and mass of a full-scale tension cone IAD. Detailed tabulated results from the tests summarized here will be presented in a series of NASA reports under preparation. These results should provide researchers with a useful database for the validation of CFD and FSI analyses of tension cone IADs.

\section{Acknowledgments}

The research presented in this paper was sponsored by NASA's Program to Advance Inflatable Decelerators for Atmospheric Entry (PAIDAE). We thank the staffs of the LaRC UPSWT and GRC SWT for their support in

model has or does not have anti-torque panels. Differences in axial force coefficients among inflatable models (i.e., with or without anti-torque panels), and between these models and the semi-rigid models are likely due to the inflation tubes. This observation is also applicable to the axial force measured during deployment and inflation as discussed in section IV.E. 
planning and conducting the tests. We are grateful for the help of the engineering and manufacturing staffs at ILC Dover in designing and fabricating the textile models.

\section{References}

${ }^{1}$ Clark, I. G., Hutchings, A. L., Tanner, C. L., and Braun, R. D., "Supersonic Inflatable Aerodynamic Decelerators for Use on Future Robotic Missions to Mars," IEEEAC Paper 1419, 2008.

${ }^{2}$ Jackson Jr., C. M. and Corlett, W. A., "Description and Calibration of the Langley Unitary Plan Wind Tunnel, NASA TP-1905," 1981.

${ }^{3}$ Soeder, R. H., Roeder, J. W., Linne, A. A., and Panek, J. W., "User Manual for NASA Glenn 10- by 10-Foot Supersonic Wind Tunnel," NASA TM-2004-212697, 2004.

${ }^{4}$ Anderson, M. S., Robinson, J. C., Bush, H. G., and Fralich, R. W., “A Tension Shell Structure for Application to Entry Vehicles," NASA TN D-2675, 1965.

${ }^{5}$ Devikis, W. D. and Sawyer, J. W., "Aerodynamic Characteristics of Tension Shell Shapes at Mach 3.0," NASA TN D-3633, 1966. 
Table 1. Tension cone IAD geometry.

Basic Dimensions

\begin{tabular}{|l|c|c|c|}
\hline \multicolumn{1}{|c|}{ Quantity } & Symbol & $\begin{array}{c}\text { LaRC UPWT } \\
\text { Rigid Model }\end{array}$ & $\begin{array}{c}\text { GRC SWT Semi-Rigid } \\
\text { and Inflatable Models }\end{array}$ \\
\hline Aeroshell diameter & $D_{A}$ & 1.8447 & 7.2624 \\
\hline Torus diameter & $D_{T}$ & 0.7500 & 2.9528 \\
\hline Total diameter & $D_{T o t}$ & 6.0000 & 23.6220 \\
\hline Tension shell diameter & $D_{T S}$ & 5.2500 & 20.6693 \\
\hline $\begin{array}{l}\text { Distance from aeroshell shoulder } \\
\text { centerline plane to aeroshell nose }\end{array}$ & $L_{S R}$ & 0.3519 & 1.3855 \\
\hline Aeroshell nose radius & $R_{N}$ & 0.4743 & 1.8675 \\
\hline Aeroshell shoulder radius & $R_{S}$ & 0.0527 & 0.2075 \\
\hline Aeroshell half-cone angle & $\theta_{A}$ & $70^{\circ}$ & $70^{\circ}$ \\
\hline Tension shell half-cone angle & $\theta_{T S}$ & $60^{\circ}$ & $60^{\circ}$ \\
\hline
\end{tabular}

Tension Shell Coordinates

\begin{tabular}{|c|c|c|c|}
\hline \multicolumn{2}{|c|}{ LaRC UPWT Rigid Model } & \multicolumn{2}{c|}{$\begin{array}{c}\text { GRC SWT Semi-Rigid } \\
\text { and Inflatable Models }\end{array}$} \\
\hline $\begin{array}{c}\text { Axial } \\
\text { Coordinate }\end{array}$ & $\begin{array}{c}\text { Radial } \\
\text { Coordinate }\end{array}$ & $\begin{array}{c}\text { Axial } \\
\text { Coordinate }\end{array}$ & $\begin{array}{c}\text { Radial } \\
\text { Coordinate }\end{array}$ \\
\hline 0.0000 & 0.0000 & 0.0000 & 0.0000 \\
\hline 0.0717 & 0.1277 & 0.2822 & 0.5026 \\
\hline 0.1409 & 0.2589 & 0.5547 & 1.0194 \\
\hline 0.2052 & 0.3902 & 0.8078 & 1.5361 \\
\hline 0.2643 & 0.5214 & 1.0404 & 2.0528 \\
\hline 0.3179 & 0.6527 & 1.2515 & 2.5696 \\
\hline 0.3658 & 0.7839 & 1.4401 & 3.0863 \\
\hline 0.4078 & 0.9152 & 1.6056 & 3.6030 \\
\hline 0.4437 & 1.0464 & 1.7470 & 4.1198 \\
\hline 0.4734 & 1.1777 & 1.8638 & 4.6365 \\
\hline 0.4967 & 1.3089 & 1.9553 & 5.1532 \\
\hline 0.5133 & 1.4402 & 2.0210 & 5.6700 \\
\hline 0.5233 & 1.5714 & 2.0604 & 6.1867 \\
\hline 0.5266 & 1.7027 & 2.0733 & 6.7034 \\
\hline
\end{tabular}

Notes

Dimensions given as-designed. Test data analyses were conducted with the as-measured values of $D_{\text {Tot }}$ for each model.

All linear dimensions in inches.

All models are geometrically similar as-designed except for as noted in the text.

Axial and radial coordinates for the tension shell use the origin specified in figure 1 . 

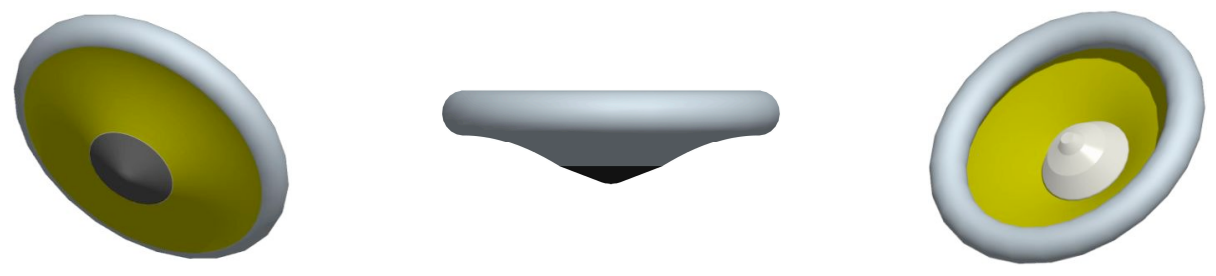

Figure 1. Tension cone inflatable aerodynamic decelerator.
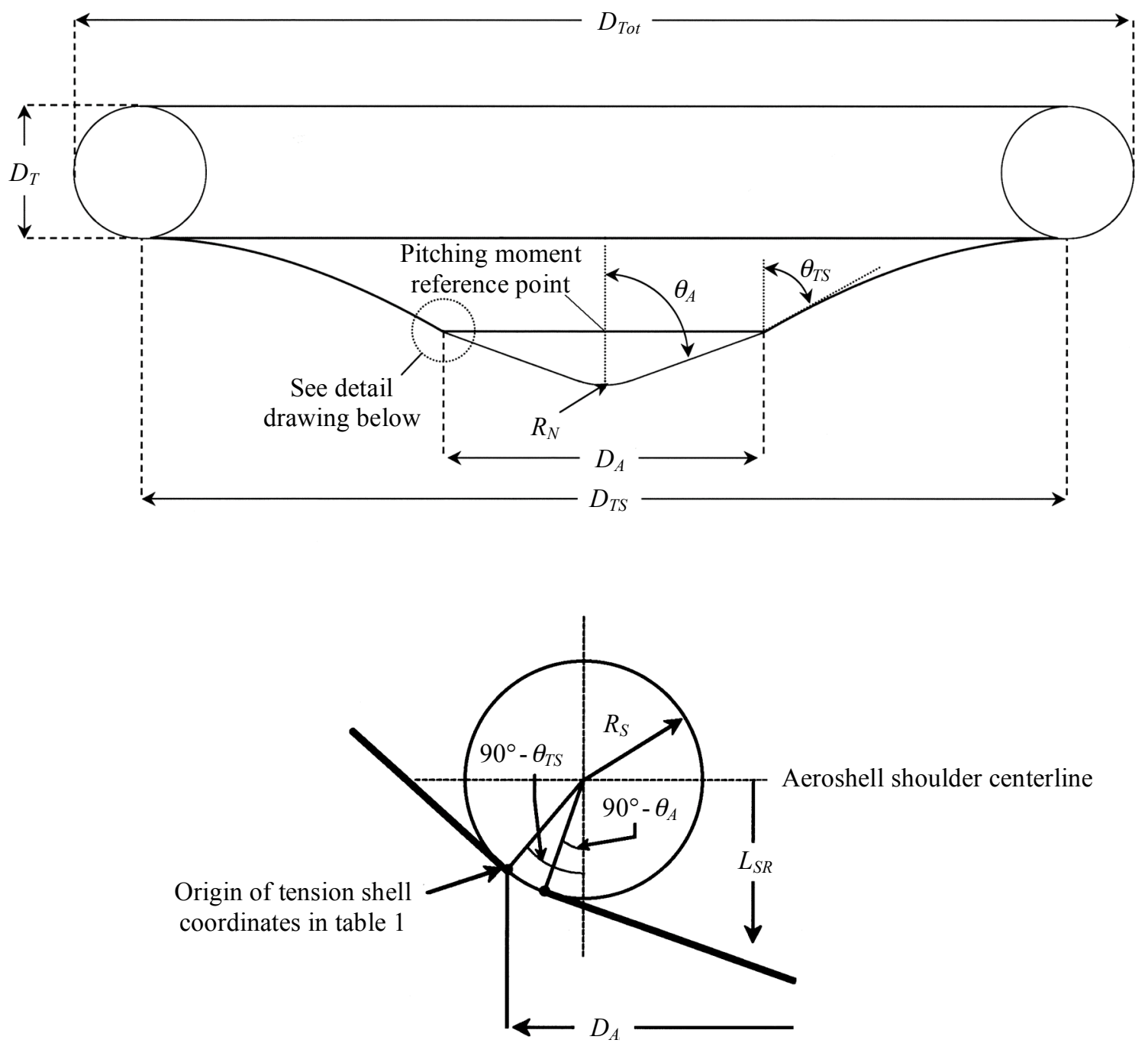

Figure 2. Tension cone IAD geometry. The pitching moment reference point is at the intersection of the model centerline and the plane defined by the aeroshell shoulder centerline (i.e., at the model centerline at a distance $L_{S R}$ aft of the nose). 

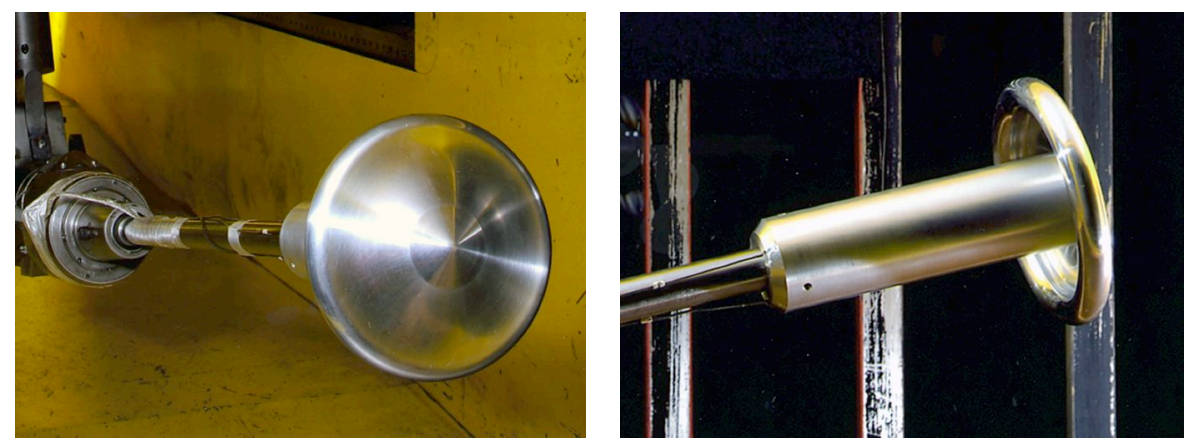

Figure 3. LaRC UPWT static aerodynamic coefficients rigid model front and rear views.

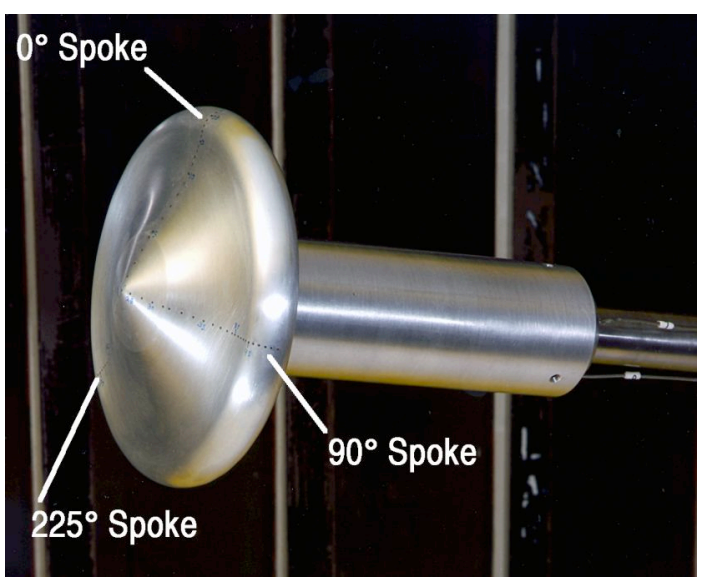

Figure 4. LaRC UPWT surface pressures coefficients rigid model showing the three spokes of pressure ports.

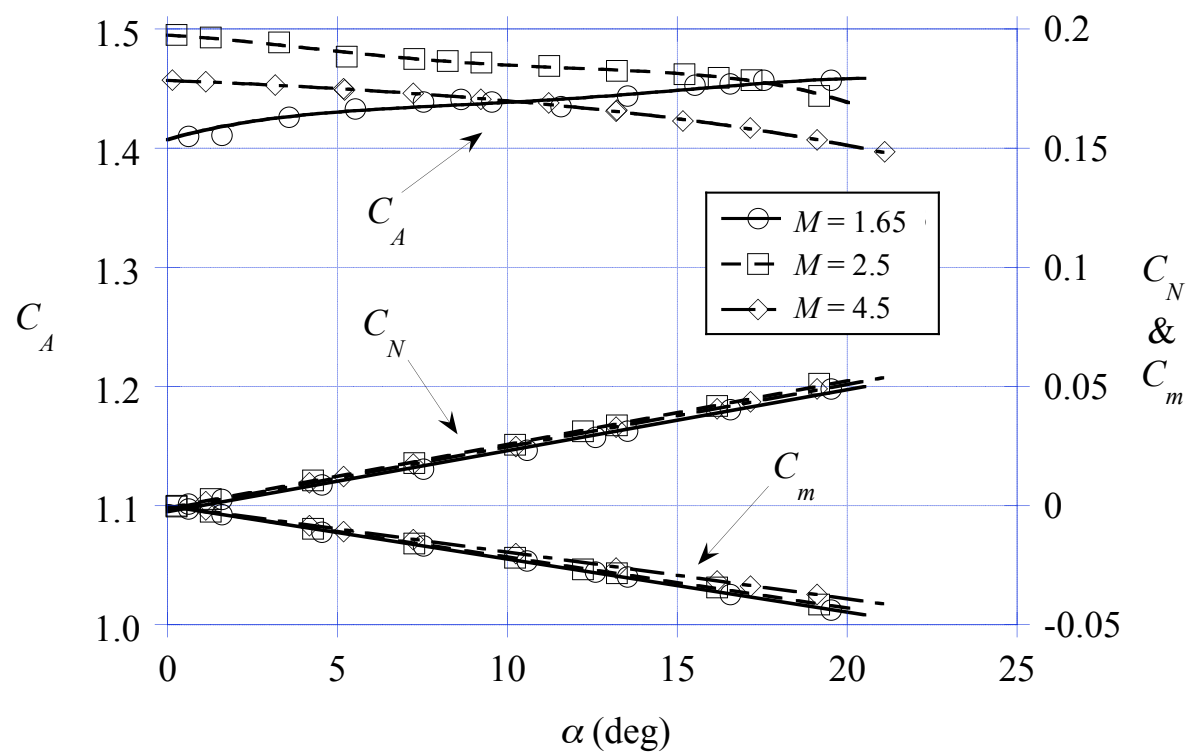

Figure 5. Static aerodynamic coefficient results obtained from the LaRC UPWT rigid model. $R e=1.0 \times 10^{6}$. Estimated total uncertainties at the 95-percent confidence level are: at $M=1.65, U_{C_{A}}=0.012, U_{C_{N}}=0.0020$, $U_{C_{m}}=0.0015$; at $M=2.5, U_{C_{A}}=0.021, U_{C_{N}}=0.0022, U_{C_{m}}=0.0018$; at $M=4.5, U_{C_{A}}=0.029, U_{C_{N}}=0.0040$, $U_{C_{m}}=0.0030$. 


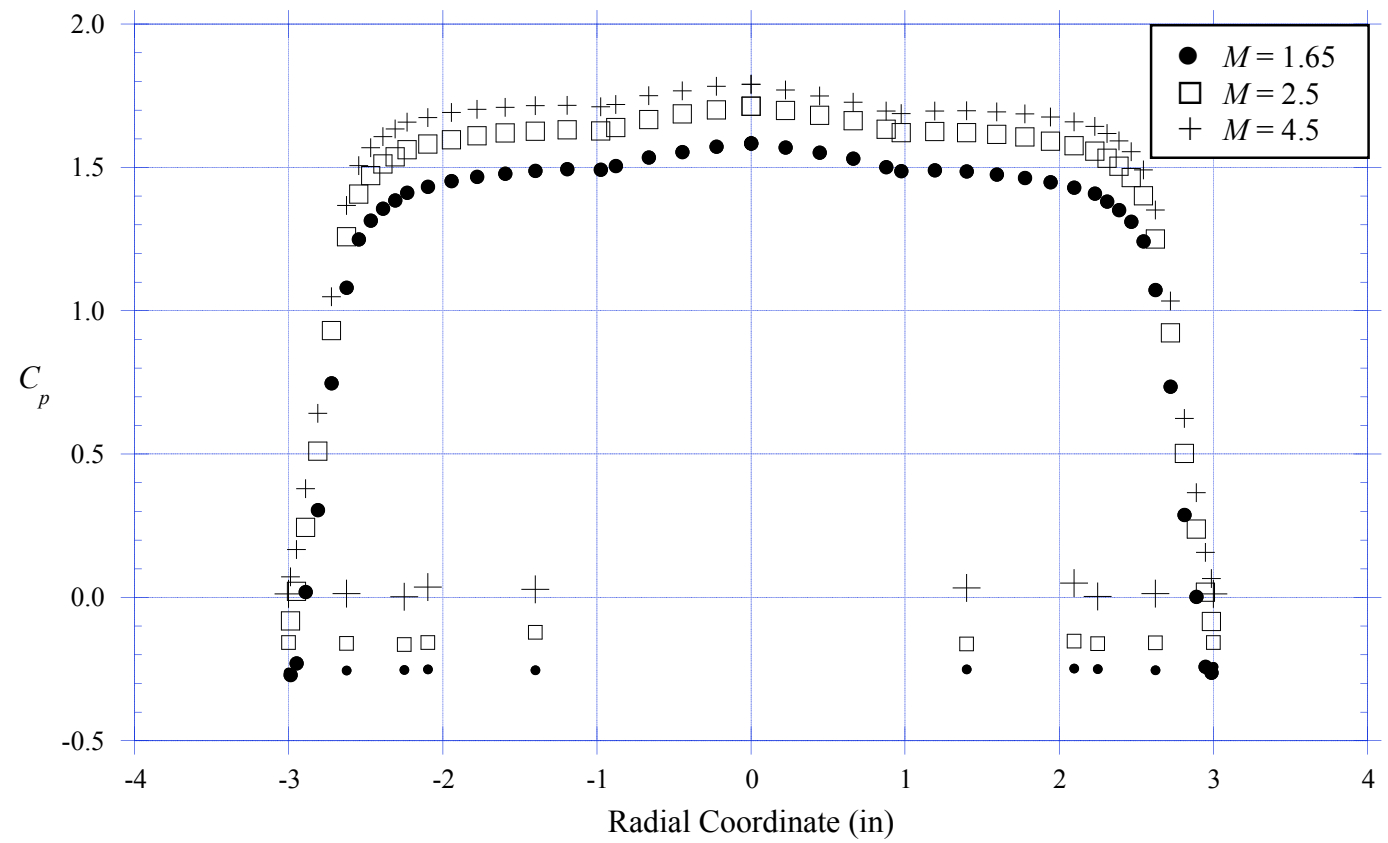

Figure 6. Effect of Mach number on the surface pressure coefficient results obtained from the LaRC UPWT rigid model. $R e=1.0 \times 10^{6}$. Data for the 0 -degree (vertical) pressure ports spoke. Angle of attack approximately zero degrees (at $M=1.65, \alpha=0.6^{\circ}$ for positive radial coordinates and $\alpha=0.4^{\circ}$ for negative radial coordinates; at $M=2.5 \alpha=0.3^{\circ}$; at $M=4.5 \alpha=1.0^{\circ}$ for positive radial coordinates and $\alpha=0.9^{\circ}$ for negative radial coordinates). Vertical dimensions of symbols are the estimated total uncertainties for individual observations of the pressure coefficients at the 95-percent confidence level.

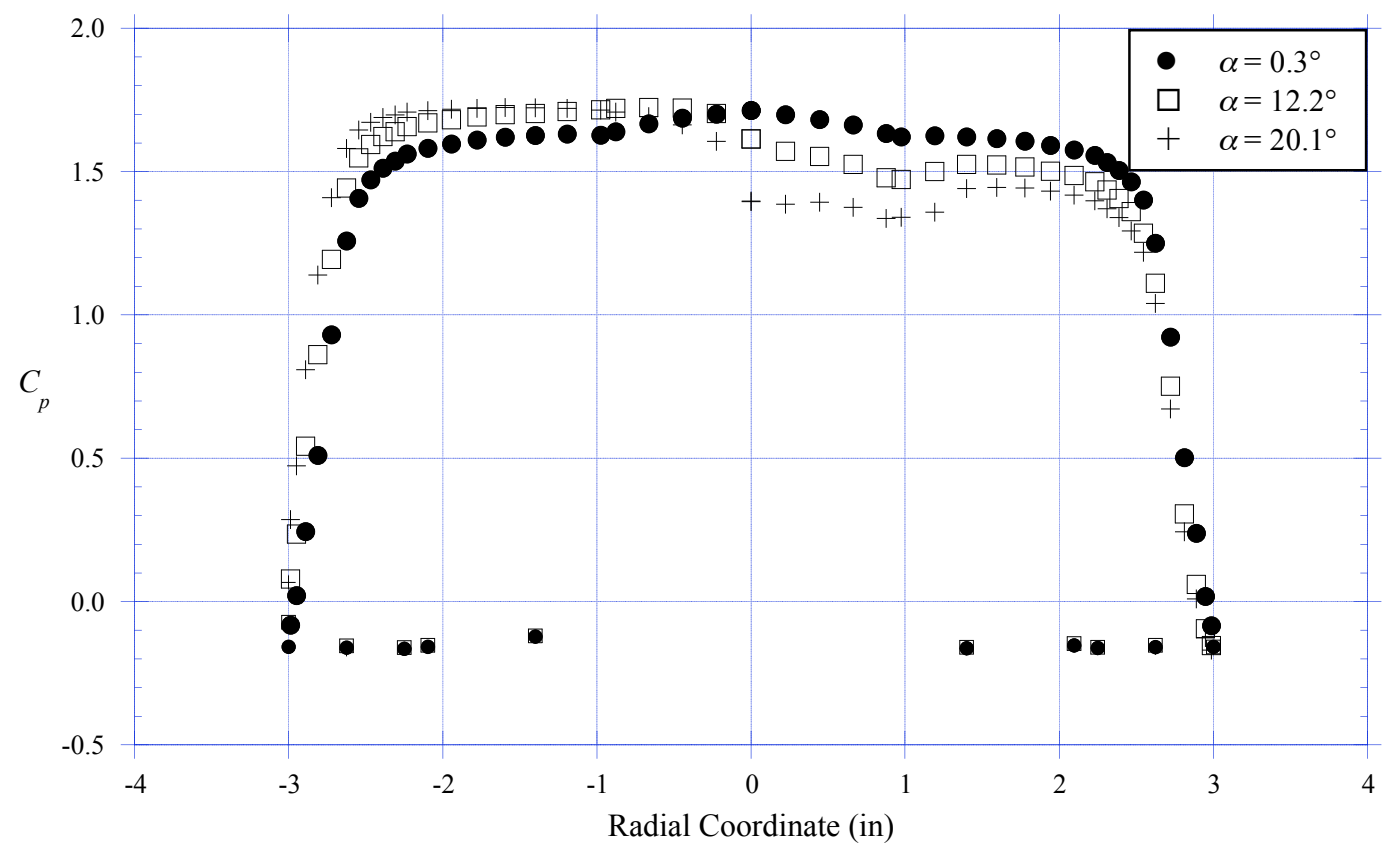

Figure 7. Effect of angle of attack on surface pressure coefficient results obtained from the LaRC UPWT rigid model. $M=2.5, R e=1.0 \times 10^{6}$. Data from the 0 -degree (vertical) pressure ports spoke. Vertical dimensions of symbols are the estimated total uncertainties for individual observations of the pressure coefficients at the 95 -percent confidence level. 

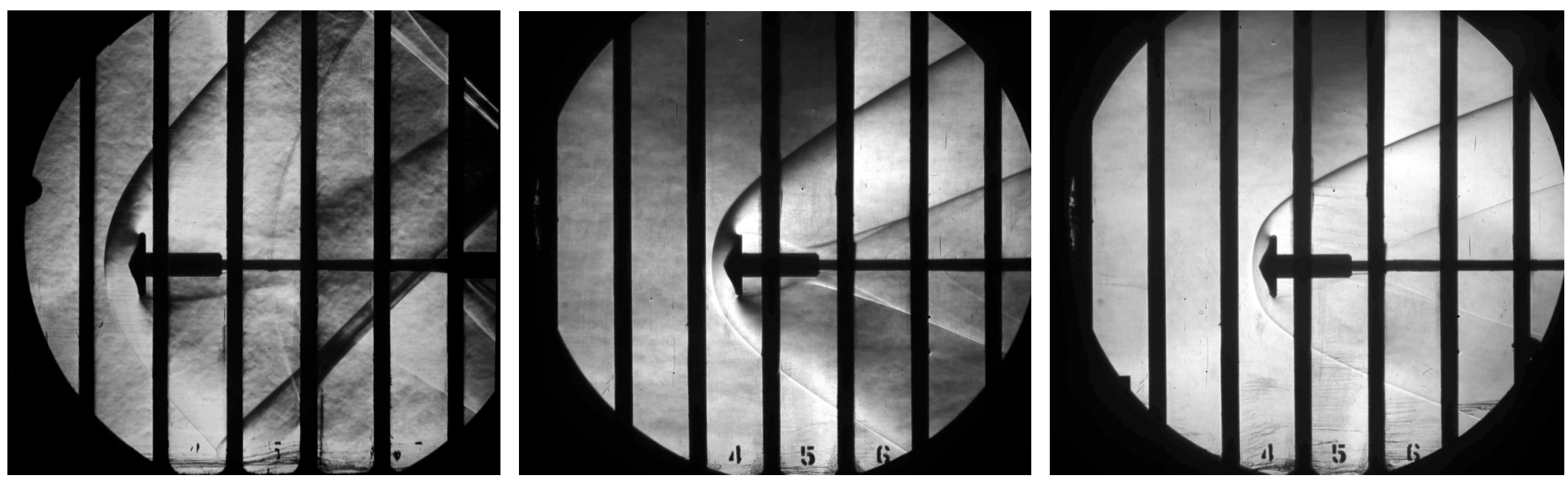

Figure 8. Effect of Mach number on the flow surrounding the LaRC UPWT rigid model at approximately zero degree angle of attack as shown by schlieren images. From left to right: $M=1.65, \alpha=0.3^{\circ} ; M=2.5, \alpha=0.3^{\circ} ; M=4.5, \alpha=1.2^{\circ}$. $R e=1.0 \times 10^{6}$.
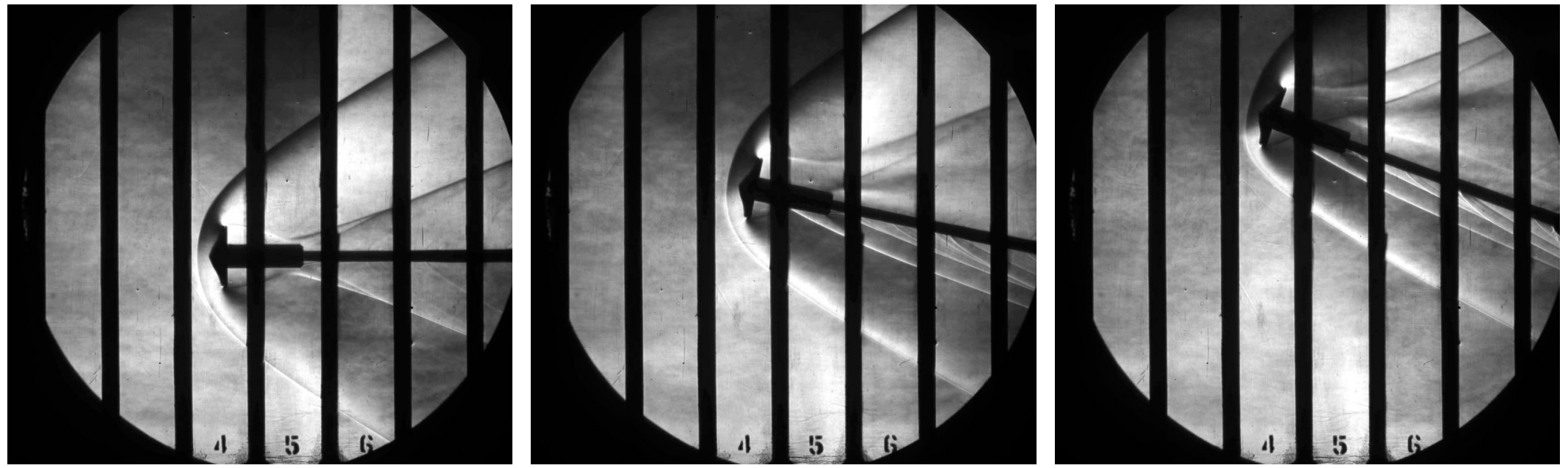

Figure 9. Effect of angle of attack on the flow surrounding the LaRC UPWT rigid model at a Mach number of 2.5 and a Reynolds number of $1.0 \times 10^{6}$ as shown by schlieren images. From left to right: $\alpha=0.3^{\circ}, \alpha=12.2^{\circ}, \alpha=20.2^{\circ}$. 

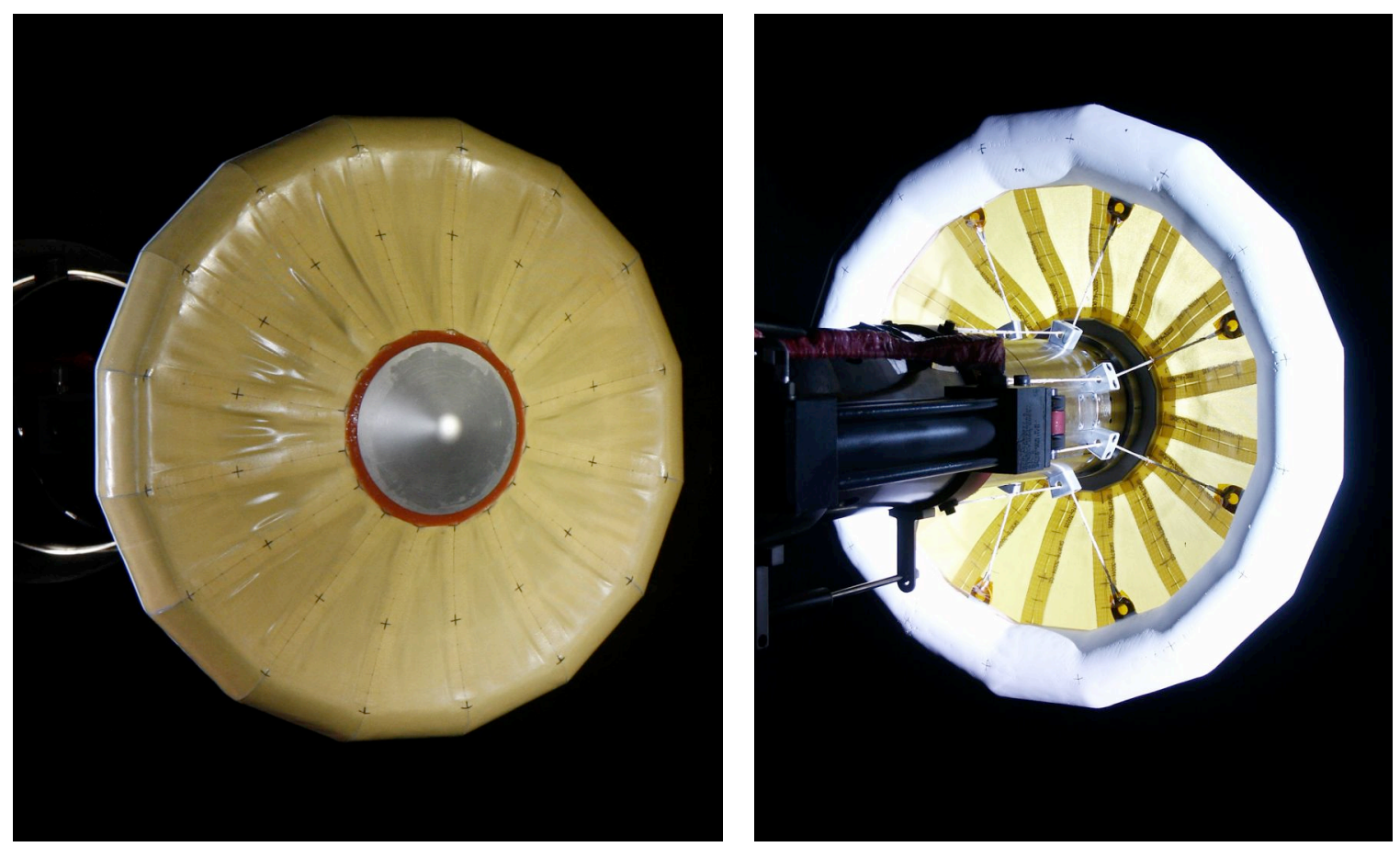

Figure 10. GRC SWT semi-rigid model. Left image is a front view with wind-on. Notice scalloping between segments of the tension shell. Right image is a rear view with wind-off. The radial cords seen in the rear view were slack during testing. These cords were pulled tight during wind tunnel startup and shutdown to limit the motion of the model as the shock passed through the test section. Model without anti-torque panels.
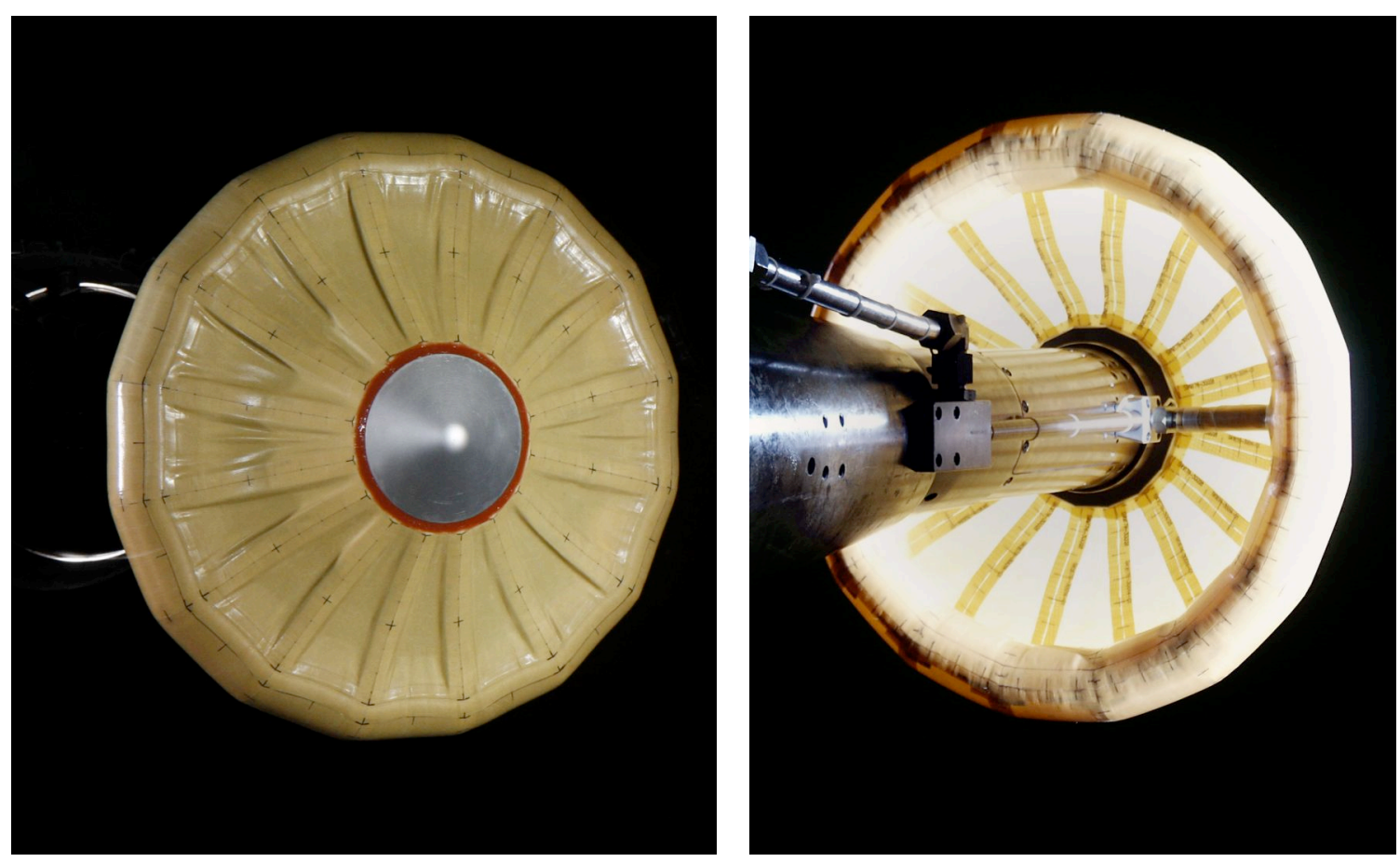

Figure 11. GRC SWT inflatable model. Left image is a front view with wind-on. Notice scalloping between segments of the tension shell. Right image is a rear view with wind-off. The right inflation tube can be seen in the rear view image at the 3:00 o'clock position. Model without anti-torque panels. 


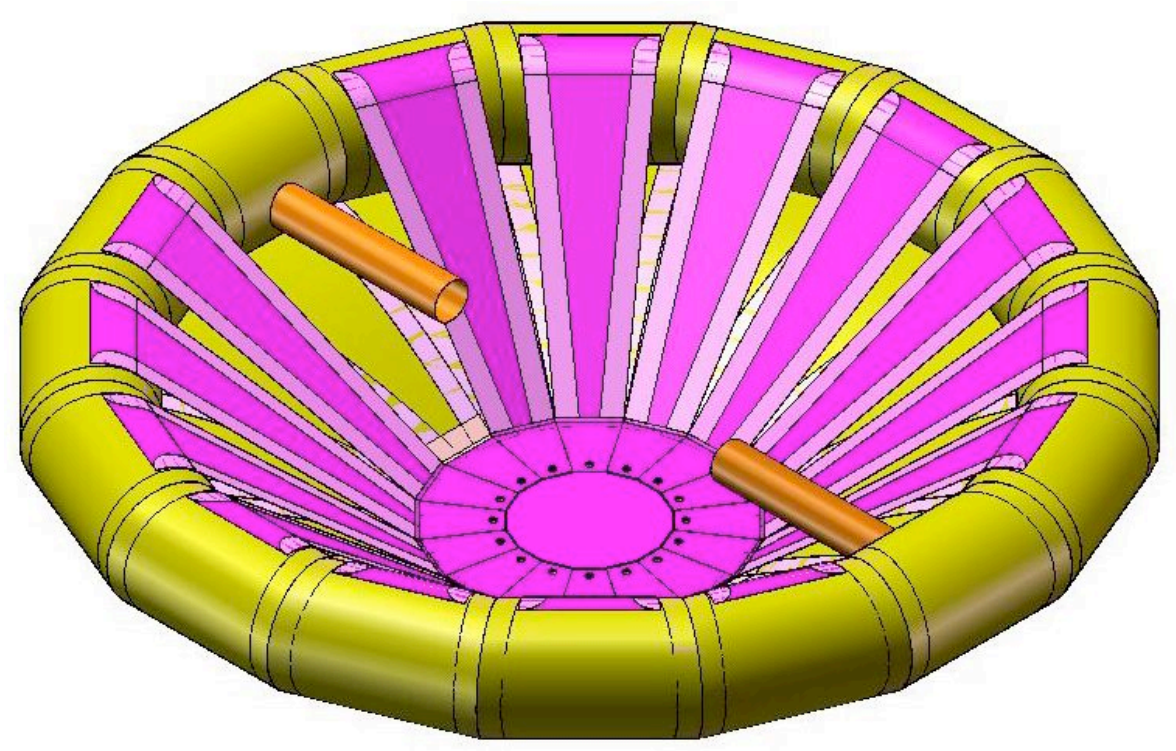

Figure 12. Anti-torque panels installation on an inflatable model.

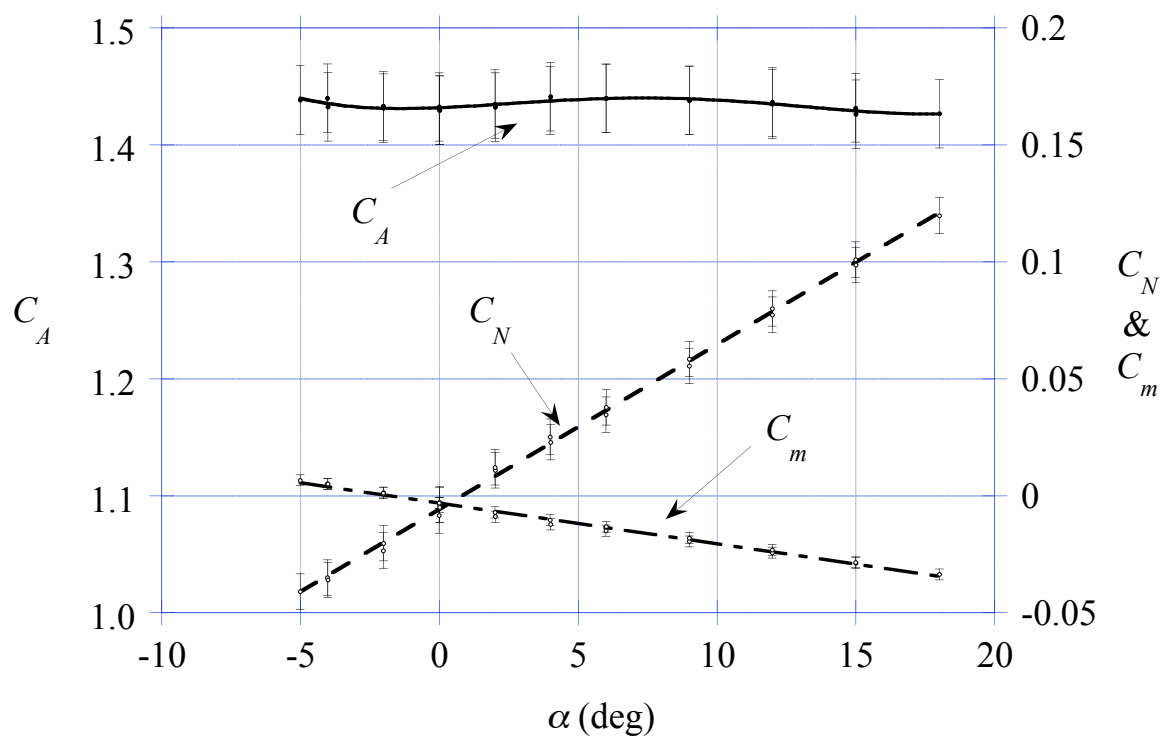

Figure 13. Static aerodynamic coefficient results obtained from the GRC SWT semi-rigid model without anti-torque panels. $M=2.44, \operatorname{Re}=1.0 \times 10^{6}, q=94.0 \mathrm{psf}$. Estimated total uncertainties shown for individual observations at the 95-percent confidence level. 


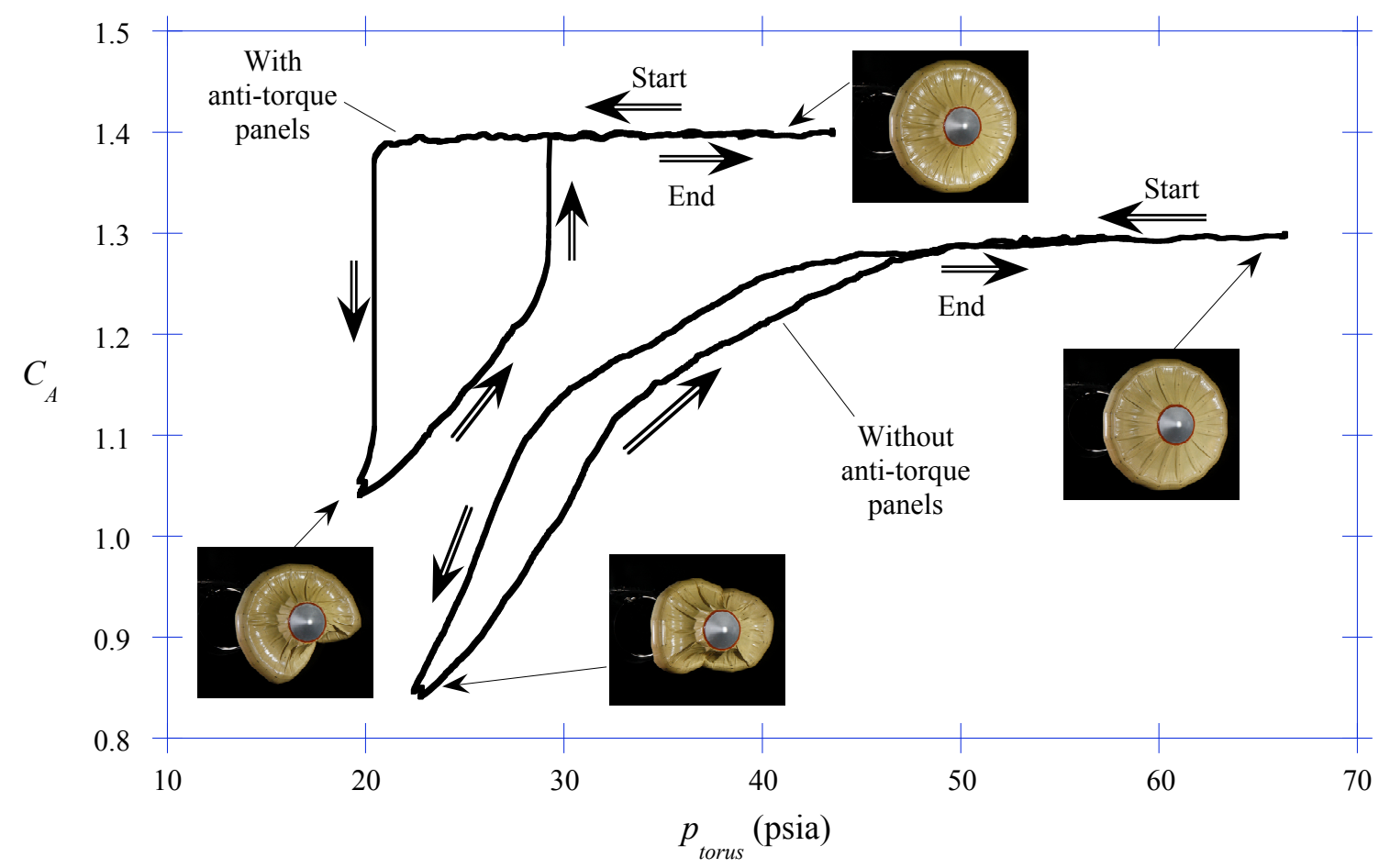

Figure 14. Pressure sweep runs for GRC SWT inflatable models with and without anti-torque panels. $M \approx 2.5$, $R e \approx 1.6 \times 10^{6}, q \approx 150 \mathrm{psf}, p_{s} \approx 35$ psia.

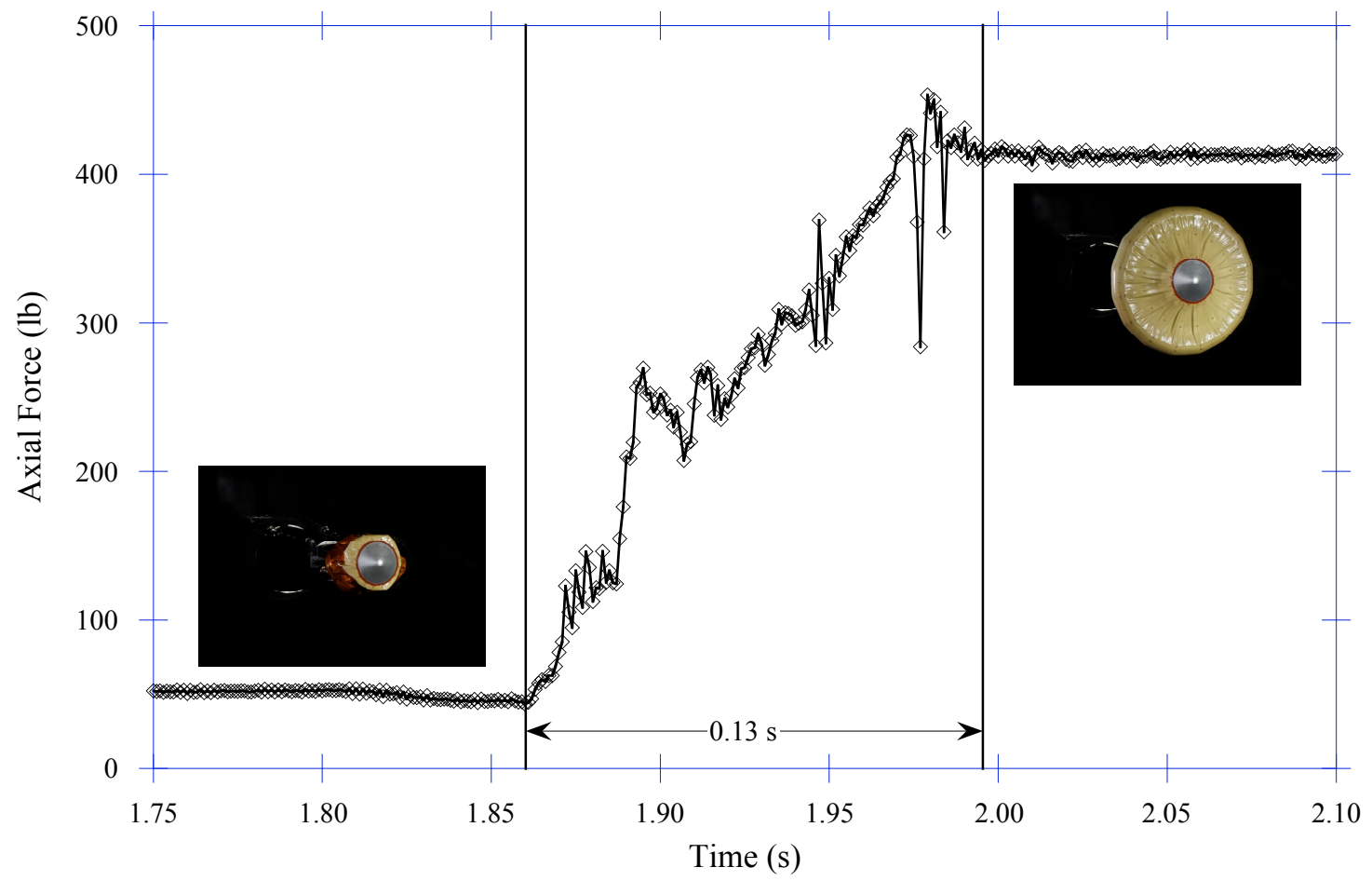

Figure 15. Deployment and inflation axial force time history for a GRC SWT inflatable model with anti-torque panels. Axial force data acquired at $1 \mathrm{kHz} . M=2.44, R e=1.0 \times 10^{6}, q=95 \mathrm{psf}, p_{s}=23 \mathrm{psf}$. Target torus inflation pressure, $p_{\text {torus }}=61$ psia. 

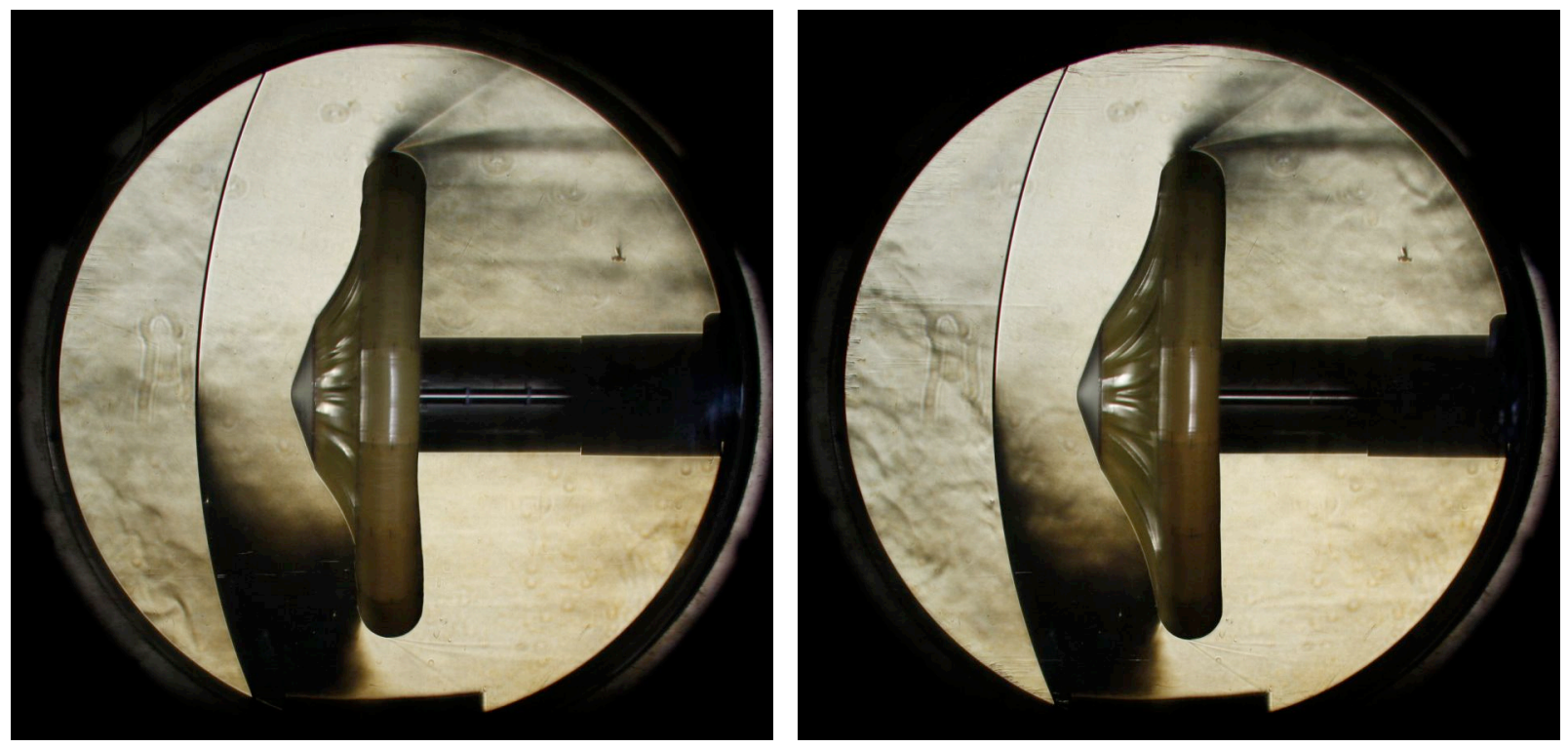

Figure 16. Schlieren images for GRC SWT inflatable models with (left, $p_{\text {torus }}=35 \mathrm{psia}$ ) and without (right, $p_{\text {torus }}=64 \mathrm{psia}$ ) anti-torque panels. Notice differences in the tension shell shape. $M \approx 2.5, \operatorname{Re} \approx 1.6 \times 10^{6}$, $q \approx 150 \mathrm{psf}, p_{s} \approx 35 \mathrm{psf}$.

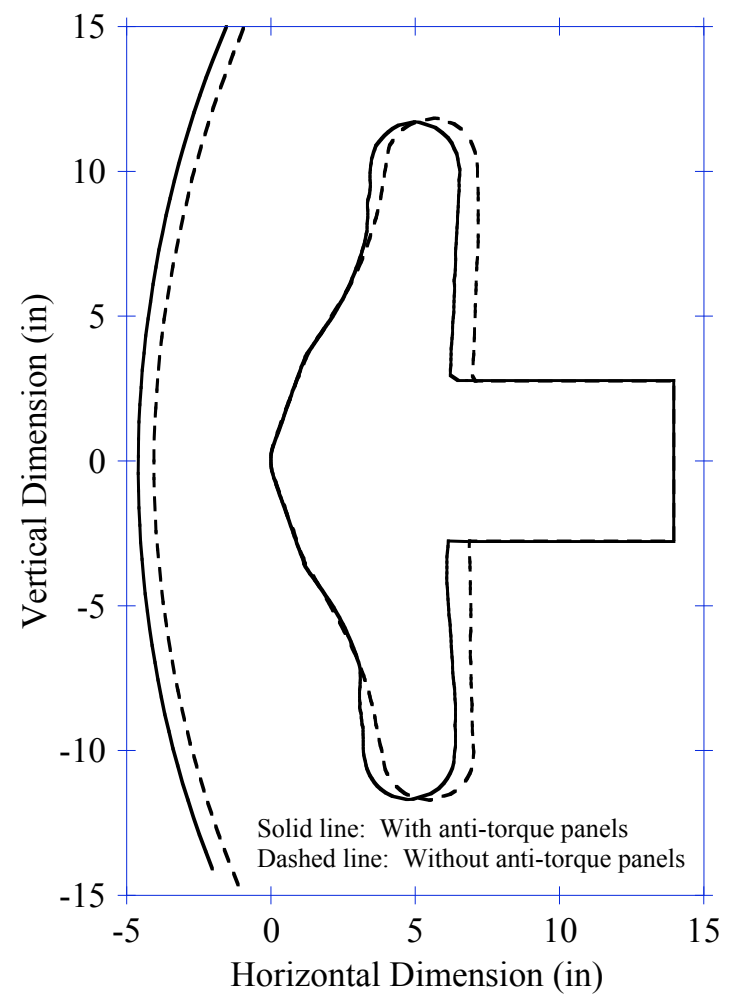

Figure 17. Profiles derived from schlieren images in figure 16 for GRC SWT inflatable models with and without anti-torque panels. Notice differences in the tension shell shape and the location of the bow shock. $M \approx 2.5$, $\operatorname{Re} \approx 1.6 \times 10^{6}, q \approx 150 \mathrm{psf}, p_{s} \approx 35$ psf. $p_{\text {torus }}=35$ psia for model with anti-torque panels. $p_{\text {torus }}=64$ psia for model without anti-torque panels. 